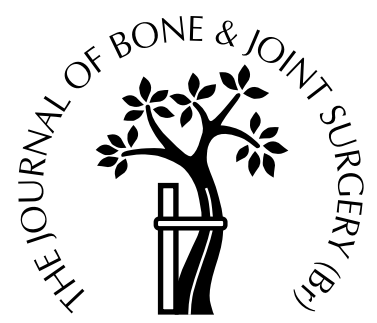

\title{
The Journal website
}

http://www.jbjs.org.uk

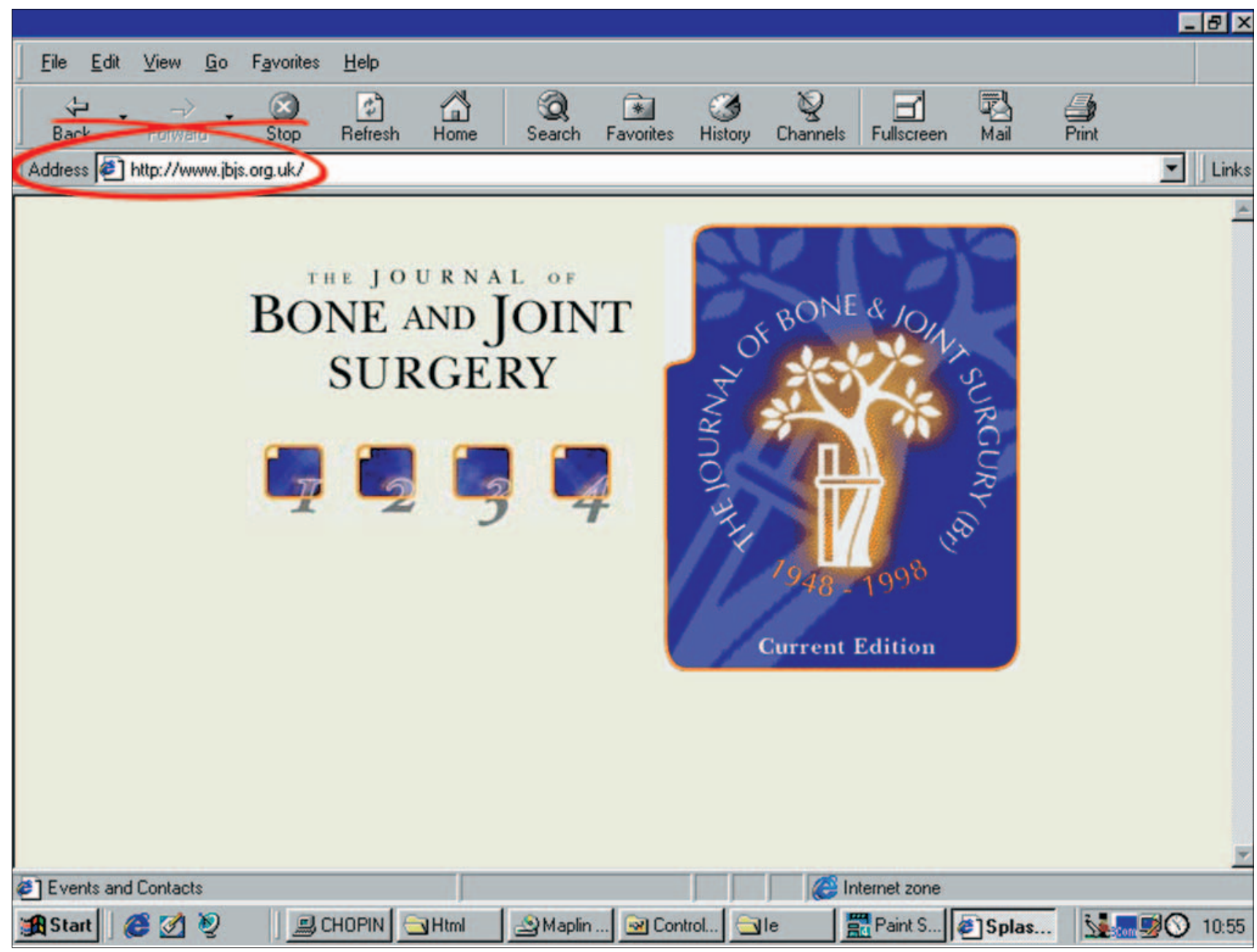

The Journal website has been upgraded and is now accessed through the address listed above. It can be viewed using versions 3.x and 4.x of Internet Explorer or Netscape Navigator on a computer which has an Internet connection. The site now contains the list of contents of the latest issue with links to the abstracts of the papers. The full text of all Editorials is available. The supplement, Orthopaedic Proceedings, which contains the abstracts from meetings of nearly 50 societies, will be placed on the website in a searchable form.

The new site provides much more information about the Journal. For example, it includes guidance on manuscript preparation for prospective authors, information for advertisers and order forms for subscribing to the Journal and its CD-ROMs. It has information on related publications such as the EFORT European Instructional Course Lectures of which the Journal is the official publisher, and links to national associations. Contacting the Journal is made easier by automatic 'mailto' links which have the relevant e-mail address in place ready for any message to be keyed. The list of Forthcoming Meetings from the latest issue of the Journal appears, again with mailto links to the organisers where available, to facilitate quick and easy communication. 